\title{
Study of Microorganisms Causing Neonatal Sepsis in a Tertiary Care Hospital and their Antimicrobial Susceptibility Pattern
}

\author{
Sabharritha Sekar ${ }^{1}$, David Agatha ${ }^{2^{*}}$ and R. Selvi ${ }^{3}$ \\ ${ }^{1}$ Department of Paediatrics, Kilpauk Medical College, Chennai-10, Tamil Nadu, India \\ ${ }^{2}$ Institute of Microbiology, Madras Medical College, Chennai-3, Tamil Nadu, India \\ ${ }^{3}$ Department of Microbiology, Stanley Medical College, Chennai-1, Tamil Nadu, India \\ *Corresponding author
}

\begin{tabular}{|c|c|}
\hline & A B S T R A C T \\
\hline & \multirow{6}{*}{$\begin{array}{l}\text { Neonatal sepsis is a clinical syndrome characterized by signs and symptoms of infection } \\
\text { with or without accompanying bacteremia in the first month of life. It encompasses various } \\
\text { systemic infections of the newborn such as septicemia, meningitis, pneumonia, arthritis, } \\
\text { osteomyelitis and urinary tract infections. A total of } 50 \text { suspected cases of Neonatal sepsis } \\
\text { in a Tertiary care hospital were studied for } 2 \text { months (August } 2011 \text {-September } 2011 \text { ) } \\
\text { Blood samples obtained from cases of neonatal sepsis were cultured to analyse for } \\
\text { bacteriological profile and antibiotic sensitivity pattern. Gram negative bacterial isolates } \\
\text { obtained were analysed for extended spectrum beta lactamase (ESBL) production and } \\
\text { Staphylococcus aureus and Coagulase negative staphylococci (CONS) isolates obtained } \\
\text { were analysed for methicillin resistance by phenotypic method. Out of the } 50 \text { blood } \\
\text { samples collected blood culture was positive in } 31(62 \%) \text { and } 31 \text { bacterial isolates were } \\
\text { obtained. Out of the } 31 \text { bacterial isolates } 26(83.88 \%) \text { were gram negative bacteria and } \\
5(16.12 \%) \text { were gram positive bacteria. Twelve }(46.15 \%) \text { of the } 26 \text { gram negative bacteria } \\
\text { were ESBL producers. All the ESBL producers }(100 \%) \text { were sensitive to imipenem. One } \\
\text { (50\%) of } 2 \text { Staphylococcus aureus and } 2(66.67 \%) \text { of the } 3 \text { CONS were methicillin } \\
\text { resistant. All the methicillin resistant Staphylococcus aureus and CONS were sensitive to } \\
\text { vancomycin. This study emphasizes the need for routine bacterial surveillance and study of } \\
\text { their resistance pattern in neonatal care for implementation of a rational empirical } \\
\text { treatment strategy. }\end{array}$} \\
\hline Keywords & \\
\hline $\begin{array}{l}\text { Neonatal sepsis, } \\
\text { Blood culture, } \\
\text { MRSA, ESBL, } \\
\text { Phenotypic } \\
\text { confirmatory test. }\end{array}$ & \\
\hline Article Info & \\
\hline $\begin{array}{l}\text { Accepted: } \\
\text { 07 September } 2017 \\
\text { Available Online: } \\
\text { 10 October } 2017\end{array}$ & \\
\hline & \\
\hline
\end{tabular}

\section{Introduction}

Neonatal septicemia continues to be one of the commonest causes of neonatal mortality and morbidity despite advances in healthcare. Neonatal sepsis may be categorized as early onset sepsis (EOS) or late onset (LOS) according to time of onset of the disease. Presence of risk factors such as low birth weight or preterm baby, febrile illness in the mother 2 weeks prior to delivery, foul smelling or meconium stained liquor, prolonged rupture of membrane, prolonged labor /difficult labor, perinatal asphyxia have been associated with increased risk of early onset sepsis (Reeta Rasaily January-March 2009). Organism that colonize in the mother's genitourinary tract may cause transplacental infection or an ascending infection from the cervix. The infant may also acquire microbe by passage through a colonized birth canal at delivery. The infant's skin, respiratory tract, 
conjunctiva, gastrointestinal tract and umbilicus may become colonized from environment leading to the possibility of late onset sepsis from invasive microorganism (Reeta Rasaily, January-March 2009).

The reported incidence of neonatal sepsis varies from 7.1 to 38 per 1000 live births in Asia (Shrestha et al., 2011). It is estimated that up to $20 \%$ of neonates develop sepsis and approximately $1 \%$ die of serious systemic infections. In developing countries, sepsis including meningitis, respiratory infections, diarrhea, and neonatal tetanus is the commonest cause of mortality responsible for 30-50 per cent of 5 million total neonatal deaths each year. The present study was done to identify the bacteria causing Neonatal sepsis and their antimicrobial susceptibility and resistance pattern to institute early and effective antibiotic therapy.

\section{Materials and Methods}

Study design and duration of study: This cross sectional study was done over a period of two months.

Sample size: 50

Inclusion criteria: Neonates suspected to have sepsis, temperature $99 \circ \mathrm{F}$, respiratory rate more than $60 / \mathrm{min}$, change in behaviour, abnormal cry, not accepting feed, drowsy or unconscious, septic focus on skin or umblicus, diarrhea, seizures were included

Exclusion criteria: Clinically not suspected septic neonates, no characteristics indicating probable sepsis and prior antibiotic administration were excluded.

A total of 50 suspected cases of Neonatal sepsis were included in the study. One to two millilitre of blood was collected from each patient under strict aseptic precautions and inoculated immediately into $5 \mathrm{ml}$ of brain heart infusion broth aseptically with utmost care.

The broths were sub-cultured after overnight incubation at $37{ }^{\circ} \mathrm{C}$ on chocolate agar, MacConkey agar and 5\% sheep blood agar along with direct gram smear from the specimen. A negative result was followed up by examining the broth daily and doing a final subculture at the end of 7 days along with a gram smear or at appearance of turbidity, whichever was earlier. Any growth was identified based on colony morphology, Gram staining, motility and standard biochemical tests (Bailey and Scott's Diagnostic Microbiology $12^{\text {th }}$ edition). The Antimicrobial susceptibility testing was performed by the Kirby-Bauer disc diffusion method in the Mueller Hinton agar medium (MHA).

For gram negative bacilli belonging to enterobacteriaceae the antimicrobial susceptibility testing included ampicillin

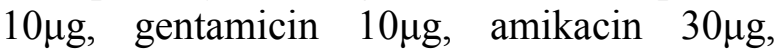
ciprofloxacin $5 \mu \mathrm{g}, \quad$ cefotaxime $30 \mu \mathrm{g}$, ceftazidime $30 \mu \mathrm{g}$ and for non-fermenters it included gentamicin $10 \mu \mathrm{g}$, amikacin $30 \mu \mathrm{g}$, ciprofloxacin $5 \mu \mathrm{g}$ and ceftazidime $30 \mu \mathrm{g}$ discs. All the gram negative isolates that showed resistance to third generation cephalosporins were evaluated for ESBL production by using phenotypic confirmatory test.

\section{Phenotypic confirmatory test}

Antibiotic sensitivity testing was done on Mueller Hinton agar with 0.5 Mc Farland's standard of the test isolate. The drugs used were cefotaxime and ceftazidime each $30 \mu \mathrm{g}$ alone and in combination with clavulanic acid $10 \mu \mathrm{g}$. Organisms with $5 \mathrm{~mm}$ increase in zone of inhibition with third generation cephalosporin and clavulanic acid, were confirmed as ESBL's.

Quality control strains- non ESBL producing organism (Escherichia coli ATCC 25922) and 
an ESBL producing organism (Klebsiella pneumoniae ATCC 700603) were used as controls.

The antimicrobial susceptibility testing for Staphylococcus aureus and Coagulase negative staphylococci included cefazolin $30 \mu \mathrm{g}$, cefotaxime $30 \mu \mathrm{g}$, gentamicin $10 \mu \mathrm{g}$, amikacin $30 \mu \mathrm{g}$, ciprofloxacin $5 \mu \mathrm{g}$ and cefoxitin $30 \mu \mathrm{g}$ discs.

\section{Cefoxitin disc diffusion test}

Cefoxitin disc diffusion testing is now recommended by CLSI as a preferred method of detection of oxacillin resistance in staphylococci. However it is important to report the findings from cefoxitin disc diffusion test as indicative of either oxacillin susceptibility/resistance; cefoxitin report should not be reported. All the isolates were subjected to cefoxitin disc diffusion test using a $30 \mu \mathrm{g}$ disc. A $0.5 \mathrm{Mc}$ Farland standard suspension of the isolate was made and lawn culture done on MHA plate. Plates were incubated at $37^{\circ} \mathrm{C}$ for $18-24 \mathrm{hrs}$ and zone diameters measured. An inhibition zone diameter of $\leq 21 \mathrm{~mm}$ for Staphylococcus aureus and $\leq 24 \mathrm{~mm}$ for CONS was reported as oxacillin resistant.

Quality control strains-Methicillin sensitive $S$. aureus (MSSA) ATCC 25923 and methicillin resistant S. aureus (MRSA) ATCC43300 were used as negative and positive controls respectively.

C Reactive Protein (CRP) estimated for the study cases were noted to correlate with culture positivity.

\section{Results and Discussion}

The total number of cases was 50 of which $31(62 \%)$ were males and $19(38 \%)$ were females. Of the total 50 cases, $29(58 \%)$ cases were in the age of 1-7 days, $14(28 \%)$ in the age of 8-14 days and 7(14\%) in the age of 1528 days. In this study $32(64 \%)$ were term neonates and $18(36 \%)$ were preterm; $32(64 \%)$ neonates belonged to low birth weight category <2500 grams and 18(36\%) neonates birth weight was >2500 grams. The presenting symptoms in most of the neonates were respiratory distress $34(68 \%)$, refusal of feeds 17(34\%), lethargy 13(26\%), fever 12(24\%), abdominal distension 9(18\%), jaundice 6(12\%) and convulsion 4(8\%). Blood culture yielded growth of bacteria in $31(62 \%)$ cases and it was negative in $19(38 \%)$ cases.

Organisms isolated by blood culture in 31 neonates with sepsis are given in Table 1 . Gram negative bacteria (83.88\%) were predominantly isolated. The antibiotic sensitivity pattern of enterobacteriaceae, nonfermenters and gram positive isolates are shown in Tables 2, 3 and 4, respectively. Table 5 shows ESBL production by gram negative bacteria. All ESBL producers were sensitive to imipenem.

Out of the 2 Staphylococcus aureus obtained $1(50 \%)$ was found to be MRSA and out of 3 CONS obtained 2(66.67\%) was found to be MRCONS. All the MRSA and MRCONS were sensitive to vancomycin.

Correlation of CRP positivity with culture positivity is shown in Table 6 . The $p$ value for the same is.0003 which is statistically significant.

In our study $62 \%$ were males and $38 \%$ were females (male: female ratio- 1.6:1).DO Awoniyi et al., (2009) also showed that prevalence of bacterial infection was higher in samples from male $(65 \%)$ neonates. Jain et al., (2003) have reported a male: female ratio of 2:1. Bhat et al., (2011) reported a male to female ratio of 1.6:1 which is similar to our result. 
The culture positivity rate in our study was 62\%. Tallur et al., (2000) reported a culture positivity rate of $64 \%$. Roy et al., (2002) reported a culture positivity rate of $47.5 \%$. Similar report $(62.8 \%)$ was reported by Rahman et al., (2002). However, culture positivity was only $26.9 \%$ in a study by Mane et al., (2010). This may be because of the larger sample size.

In our study neonatal sepsis was common in low birth neonates. Khatua et al., (1986) reported a higher incidence of sepsis in low birth weight infants. Prematurity and low birth weight was identified as a significant neonatal risk factor by Shah et al., (2006). Premature and low birth weight babies are relatively immune deficient, which predispose them to infections. Moreover, these babies are likely to be subjected to different interventional procedures leading to nosocomial infections.

An area based knowledge of the bacteriological spectrum is essential because the first antibiotic administered will not wait for the culture results and keeping in mind the high morbidity and mortality associated with neonatal sepis, a right choice of such empiric therapy is of utmost importance. In our study gram negative organisms $(83.8 \%)$ were predominantly isolated. In a study by (Bhat et al., 2011) $90.2 \%$ of isolates were gram negative bacteria. Predominance of gram negative isolates (67.2\%-92.5\%) has been reported by developing countries. Mane et al., (2010) also reported that Gram negative bacteria $(61.3 \%)$ are predominant organisms causing neonatal sepsis. In a study by (Rushda Aftab et al., March 2009) gram negative organisms were isolated in $67 \%$ of the total isolates.

The pathogens most often implicated in neonatal sepsis in developing countries differ from those seen in developed countries. Group B Streptococci is extremely rare in developing countries but is frequently an important pathogen in developed countries. In our study Group B Streptococci was not isolated from any of the cases. The spectrum of bacteria causing neonatal sepsis in our study is comparable to the national neonatal perinatal database report (Jeeva Sankar et al., 2008).

In our study Klebsiella pneumoniae (35.48\%) was the most common isolate which is similar to the other Indian studies (Roy et al., 2002; Mane et al., 2010; Bhat et al., 2011). We obtained $16.12 \%$ of Pseudomonas aeruginosa. Bhat et al., (2011) reported Pseudomonas $(33.2 \%)$ to be the most common pathogen causing neonatal sepsis. Pseudomonas isolation rate varies from $8.9 \%$ $38.3 \%$.

Table.1 Organisms isolated by blood culture in neonates with sepsis $(n=31)$

\begin{tabular}{|l|c|c|}
\hline Name of the organism isolated in blood culture & Number & Percentage \\
\hline Klebsiella pneumoniae & 11 & $35.48 \%$ \\
\hline Pseudomonas aeruginosa & 5 & $16.12 \%$ \\
\hline Coagulase negative Staphylococci & 3 & $9.68 \%$ \\
\hline Acinetobacter species & 3 & $9.68 \%$ \\
\hline Proteus mirabilis & 3 & $9.68 \%$ \\
\hline Proteus vulgaris & 1 & $3.23 \%$ \\
\hline Staphylococcus aureus & 2 & $6.45 \%$ \\
\hline Escherichia coli & 1 & $3.23 \%$ \\
\hline Klebsiella oxytoca & 1 & $3.23 \%$ \\
\hline Citrobacter freundii & 1 & $3.23 \%$ \\
\hline
\end{tabular}


Int.J.Curr.Microbiol.App.Sci (2017) 6(10): 669-677

Table.2 Antibiotic Sensitivity Pattern of Enterobacteriaceae Isolates ( $\mathrm{n}=18)$

\begin{tabular}{|c|c|c|c|c|c|c|c|c|c|c|c|c|}
\hline \multirow[t]{2}{*}{ Antibiotics } & \multicolumn{2}{|c|}{$\begin{array}{l}\text { Klebsiella } \\
\text { pneumoniae }(\mathrm{n}=11)\end{array}$} & \multicolumn{2}{|c|}{$\begin{array}{l}\text { Proteus } \\
\text { mirabilis }(\mathrm{n}=3)\end{array}$} & \multicolumn{2}{|c|}{$\begin{array}{l}\text { Proteus } \\
\text { vulgaris }(\mathrm{n}=1)\end{array}$} & \multicolumn{2}{|c|}{$\begin{array}{l}\text { Klebsiella } \\
\text { oxytoca }(\mathrm{n}=1)\end{array}$} & \multicolumn{2}{|c|}{$\begin{array}{l}\text { Escherichia } \\
\text { coli }(\mathrm{n}=1)\end{array}$} & \multicolumn{2}{|c|}{$\begin{array}{l}\text { Citrobacter } \\
\text { freundii }(\mathrm{n}=1)\end{array}$} \\
\hline & $\mathrm{S}$ & $\mathrm{R}$ & $\mathrm{S}$ & $\mathrm{R}$ & $\mathrm{S}$ & $\mathrm{R}$ & $\mathrm{S}$ & $\mathrm{R}$ & $\mathrm{S}$ & $\mathrm{R}$ & $\mathrm{S}$ & $\mathrm{R}$ \\
\hline Gentamicin & 0 & $\begin{array}{l}11 \\
100 \% \\
\end{array}$ & $\begin{array}{l}1 \\
33.3 \% \\
\end{array}$ & $\begin{array}{l}2 \\
66.7 \% \\
\end{array}$ & 0 & $\begin{array}{l}1 \\
100 \% \\
\end{array}$ & 0 & $\begin{array}{l}1 \\
100 \% \\
\end{array}$ & $\begin{array}{l}1 \\
100 \% \\
\end{array}$ & 0 & 0 & $\begin{array}{l}1 \\
100 \%\end{array}$ \\
\hline Amikacin & $\begin{array}{l}5 \\
45.5 \% \\
\end{array}$ & $\begin{array}{l}6 \\
54.5 \% \\
\end{array}$ & 2 & $\begin{array}{l}1 \\
33.3 \% \\
\end{array}$ & 0 & $\begin{array}{l}1 \\
100 \% \\
\end{array}$ & $\begin{array}{l}1 \\
100 \% \\
\end{array}$ & 0 & 0 & $\begin{array}{l}1 \\
100 \% \\
\end{array}$ & 0 & $\begin{array}{l}1 \\
100 \% \\
\end{array}$ \\
\hline Ciprofloxacin & $\begin{array}{l}5 \\
45.5 \% \\
\end{array}$ & $\begin{array}{l}6 \\
54.5 \% \\
\end{array}$ & $\begin{array}{l}1 \\
33.3 \%\end{array}$ & $\begin{array}{l}2 \\
66.7 \% \\
\end{array}$ & $\begin{array}{l}1 \\
100 \%\end{array}$ & 0 & 0 & $\begin{array}{l}1 \\
100 \%\end{array}$ & $\begin{array}{l}1 \\
100 \%\end{array}$ & 0 & $\begin{array}{l}1 \\
100 \%\end{array}$ & 0 \\
\hline Cefotaxime & $\begin{array}{l}4 \\
36.3 \% \\
\end{array}$ & $\begin{array}{l}8 \\
72.7 \% \\
\end{array}$ & $\begin{array}{l}3 \\
100 \% \\
\end{array}$ & 0 & $\begin{array}{l}1 \\
100 \% \\
\end{array}$ & 0 & $\begin{array}{l}1 \\
100 \%\end{array}$ & 0 & $\begin{array}{l}1 \\
100 \% \\
\end{array}$ & 0 & $\begin{array}{l}1 \\
100 \%\end{array}$ & 0 \\
\hline Ceftazidime & $\begin{array}{l}4 \\
36.4 \% \\
\end{array}$ & $\begin{array}{l}8 \\
72.7 \% \\
\end{array}$ & $\begin{array}{l}3 \\
100 \% \\
\end{array}$ & 0 & $\begin{array}{l}1 \\
100 \% \\
\end{array}$ & 0 & $\begin{array}{l}1 \\
100 \% \\
\end{array}$ & 0 & $\begin{array}{l}1 \\
100 \% \\
\end{array}$ & 0 & $\begin{array}{l}1 \\
100 \% \\
\end{array}$ & 0 \\
\hline
\end{tabular}


Table.3 Antibiotic sensitivity of Pseudomonas aeruginosa And Acinetobacter Species

\begin{tabular}{|l|c|c|c|c|}
\hline \multirow{2}{*}{ Antibiotics } & \multicolumn{2}{|c|}{ Pseudomonas } & aeruginosa $(\mathrm{n}=5)$ & \multicolumn{2}{|c|}{ Acinetobacter species $(\mathrm{n}=3)$} \\
\cline { 2 - 5 } & Sensitive & Resistant & Sensitive & Resistant \\
\hline Ciprofloxacin & $4(80 \%)$ & $1(20 \%)$ & $1(33.3 \%)$ & $2(66.7 \%)$ \\
\hline Amikacin & $3(60 \%)$ & $2(40 \%)$ & $1(33.3 \%)$ & $2(66.7 \%)$ \\
\hline Gentamicin & 0 & $5(100 \%)$ & 0 & $3(100 \%)$ \\
\hline Ceftazidime & $2(40 \%)$ & $3(60 \%)$ & $1(33.3 \%)$ & $2(66.7 \%)$ \\
\hline
\end{tabular}

Table.4 Antibiotic sensitivity of Staphylococcus aureus and Cons

\begin{tabular}{|l|c|c|c|c|}
\hline \multirow{2}{*}{ Antibiotics } & \multicolumn{2}{|l|}{ CONS (n=3) } & \multicolumn{2}{c|}{ STAPHYLOOCCUS AUREUS (n=2) } \\
\cline { 2 - 5 } & Sensitive & Resistant & Sensitive & Resistant \\
\hline Cefazolin & $1(33.3 \%)$ & $2(66.7 \%)$ & $1(50 \%)$ & $1(50 \%)$ \\
\hline Cefotaxime & $1(33.3 \%)$ & $2(66.7 \%)$ & $1(50 \%)$ & $1(50 \%)$ \\
\hline Cefoxitin & $1(33.3 \%)$ & $2(66.7 \%)$ & $1(50 \%)$ & $1(50 \%)$ \\
\hline Gentamicin & 0 & $3(100 \%)$ & 0 & $2(100 \%)$ \\
\hline Amikacin & $3(100 \%)$ & 0 & $1(50 \%)$ & $1(50 \%)$ \\
\hline Ciprofloxacin & $2(66.7 \%)$ & $1(33.3 \%)$ & $2(100 \%)$ & 0 \\
\hline
\end{tabular}

Table.5 ESBL production by gram negative bacteria

\begin{tabular}{|l|c|c|}
\hline Isolate & Total no.of isolates (26) & ESBL producers (12) \\
\hline Klebsiella pneumoniae & 11 & $8(72.72 \%)$ \\
\hline Pseudomonas aeruginosa & 5 & $2(40 \%)$ \\
\hline Acinetobacter species & 3 & $2(66.67 \%)$ \\
\hline Proteus mirabilis & 3 & 0 \\
\hline Proteus vulgaris & 1 & 0 \\
\hline Escherichia coli & 1 & 0 \\
\hline Klebsiella oxytoca & 1 & 0 \\
\hline Citrobacter freundii & 1 & 0 \\
\hline
\end{tabular}

Table.6 Correlation of CRP positivity with culture positivity

\begin{tabular}{|c|c|c|}
\hline \multirow{2}{*}{ CRP Test } & \multicolumn{2}{|c|}{ Blood culture } \\
\cline { 2 - 3 } & Positive & Negative \\
\hline Positive(26) & 22 & 4 \\
\hline Negative(24) & 9 & 15 \\
\hline Total & 31 & 19 \\
\hline
\end{tabular}

In our study, Acinetobacter spp accounted for $9.68 \%$ of the cases.14.3\% of isolates were Acinetobacter in a study by Mane et al., (2010). Similar results (10.4\%) were reported by Agnihotri et al., (2004).
9.6\% Coagulase negative staphylococci (CONS) was obtained in this study. This bacterium is often regarded as a contaminant, possibly from the skin, but Leon et al., (1984) opined that the presence of this bacterium in 
the blood can no longer be taken as contamination especially in patients in critical care units. This view is also shared by Favre et al., (2005) who concluded their study reporting that CONS bacteremia harbor a significant mortality and a single positive blood culture in the presence of signs of sepsis should be considered as clinically relevant.

We obtained $6.45 \%$ of Staphylococcus aureus. The rates of Staphylococcus aureus infection in a study by Bhat et al., (2011) was $9.2 \%$. Similar reports with rate of infection varying from $3.7 \%-7 \%$ have been found previously. However, Karthikeyan et al., (2001) in their analysis identified Staphylococcus aureus as a predominant pathogen $(61.5 \%)$.

Multidrug resistance of the causative organisms of sepsis is a rapidly emerging, potentially disastrous problem. The situation is worst in developing countries because of the lack of control of the use of antibiotics, the non-existence of legislation on antibiotic prescription, over the counter sale of antibiotics, poor sanitary conditions, lack of basic facilities and practices such as hand washing, lack of surveillance of the standards of maternity homes, and the practices of traditional birth attendants.

Our study shows a very high degree of resistance of Gram negative organisms to first line antibiotics. All Klebsiella isolates were resistant to ampicillin and gentamicin. This suggests that the WHO recommended ampicillin and gentamicin combination for treatment of neonatal sepsis may no longer be effective in treating many newborns with sepsis.

Klebsiella pneumoniae isolates were maximally sensitive to imipenem (100\%), ciprofloxacin $(54.54 \%)$ and amikacin
(54.54\%). High degree of resistance was seen to cefotaxime and ceftazidime.

In our study Pseudomonas aeruginosa was resistant to gentamicin and ceftazidime. They were sensitive to ciprofloxacin (80\%) and amikacin (60\%).

CONS and Staphylococcus aureus isolates in our study were sensitive to ciprofloxacin and amikacin. They were resistant to gentamicin, cefazolin and cefotaxime.

Increasing resistance to third generation cephalosporins among Klebsiella and Escherichia coli is also notable. Klebsiella and Escherichia coli resistance is usually acquired via plasmid-mediated extended spectrum beta-lactamase (ESBL) production.

Owing to the presence of other resistanceconferring genes on these transferable plasmids, such organisms are also often resistant to other drugs, including aminoglycoside antibiotics.

Risk factors for acquiring ESBL organisms include heavy antibiotic use, including use of third generation cephalosporins.

In our study ESBL production was shown by $72.72 \%$ of $K$. pneumoniae isolates, followed by $66.67 \%$ of Acinetobacter isolates and $40 \%$ of Pseudomonas aeruginosa isolates.

Various authors have given different observations of ESBL production in their studies on neonatal septicemia. Kim et al., (2002) reported ESBL production by $52.9 \%$ of $K$. pneumoniae and $17.9 \%$ of Escherichia coli isolates.

Jain et al., (2003) have reported a high ESBL production by Klebsiella spp (87.2\%), Enterobacter spp (72.5\%), Escherichia coli (65.3\%) and Acinetobacter (33.3\%). 
The high percentage of ESBL producing Klebsiella species may be due to the selective pressure imposed by extensive use of antimicrobials in intensive care unit.

According to the latest report from national nosocomial infection surveillance system approximately $60 \%$ of all Staphylococcus aureus nosocomial infections in intensive care units were methicillin resistant. Karthikeyan et al., (2001) reported that $66 \%$ of Staphylococcus aureus isolated from cases of neonatal sepsis was methicillin resistant.

The degree of resistance or sensitivity of Staphylococcus aureus towards commonly used antibiotics is diverse from region to region, so it is inevitable to look for MRSA in every Staphylococcus aureus isolated.

In our study $50 \%$ of Staphylococcus aureus and $66.67 \%$ of CONS were methicillin resistant. MRSA detection was done by cefoxitin disc diffusion method.

In this study CRP was elevated in 26 cases of which 22 were confirmed bacteriologically.

Sabel et al., (1974) in their study of 14 cases of neonatal sepsis observed increased CRP in $85.7 \%$ of cases with positive blood cultures. In a study by Lakshmi et al., (1992) CRP was found to be raised in $89.47 \%$ cases of neonatal sepsis whereas blood culture was positive only in $63.15 \%$ cases. They have concluded that CRP positivity highly correlates with infection positivity.

Neonatal sepsis is a leading cause of mortality and morbidity in neonates in our country.

Bacterial spectrum causing neonatal sepsis is different in developed and developing countries Routine bacterial surveillance and study of their resistance patterns must be an essential component of neonatal care.
Periodic evaluations not only show the trend of increasing resistance to commonly used antibiotics but also help in implementation of a rational empirical treatment strategy. Present study indicated that Gram-negative bacteria continue to be the predominant causative organisms of neonatal sepsis. Gram negative bacteria showed high resistance to first line drugs like gentamicin, ampicillin and to drugs like cefotaxime. Most of them had good sensitivity to ciprofloxacin and amikacin. Imipenem is best for multidrug resistant gram negative bacilli. Increased incidence of MRSA has been found.

CRP estimation can help in the early diagnosis of neonatal sepsis.

\section{Acknowledgement}

This study was carried out as short term studentship program of ICMR.

\section{References}

Agnihotri, N., Kaistha N and Gupta V.2004; Antimicrobial susceptibility of isolates from neonatal septicemia, Jpn J Infect Dis 273-275.

Awoniyi, D.O., SJ Udo, OO Oguntibeju. July 2009; an epidemiological survey of neonatal sepsis in a hospital in western Nigeria. African journal of Microbiology research Vol.3 (6) p385-389.

Bailey \& Scott's Diagnostic Microbiology 12th edition-Betty A Forbes, Daniel F. Sahm, Alice S. Weissfeld. Mosby publishers 11830 Westline industrial drive St. Louis, Missouri 63146.

Bhat. Y., et al., 2011; Bacterial isolates of earlyonset neonatal sepsis and their antibiotic susceptibility pattern between 1998 and 2004: an audit from a center in India. Italian Journal of Pediatrics 37:32.

Favre, B., Hugonnet S, Correa L, Sax H, Rohner P et al., 2005; Nosocomial bacteremia: clinical significance of a single blood culture positive for coagulase negative 
staphylococci, Infect Control Hosp Epidemiol 26:697-702

Jain, A., Roy I, Gupta M, Kumar M and Agarwal SK. 2003; Prevalence of extended-spectrum $\beta$-lactamase-producing Gram-negative bacteria in septicaemic neonates in a tertiary care hospital, Journal of Medical Microbiology 52:421-425

Jain, N.K., Jain VM, Maheshwari S. 2003; Clinical Profile of Neonatal Sepsis. Kathmandu University Medical Journal Vol. 1, No. 2, 117-120.

Jeeva Sankar, M., Ramesh Agarwal, Ashok K Deorari and Vinod K Paul.March 2008; Sepsis in the new born.Indian journal of Pediatrics, Volume 75

Karthikeyan, G., Premkumar K. 2001; Aug Neonatal sepsis: Staphylococcus aureus as the predominant pathogen Indian J Pediatr. 68(8):715-7.

Khatua, S.P., A.K. Das, B.D. Chaterjee, S. Khatua, B. Ghose and A. Saha 1986; Neonatal septicemia. Indian Journal of Pediatrics Vol 53:pages 509-514.

Kim, Y.K., Pai H, Lee HJ, Park SE, Choi EH et al., 2002; Bloodstream infections by Extended-Spectrum $\quad \beta$-LactamaseProducing Escherichia coli and Klebsiella pneumoniae in children: Epidemiology and clinical outcome, Antimicrob Agents Chemother 46:1481-1491.

Lakshmi, N., and Guraj kumar. 1992; C-Reactive protein in neonatal sepsis. Ind $\mathbf{J}$ Med Microbiol. 10, 29-31.

Leon, S., Wenzel RP. 1984;Hospital acquired blood stream infections with Staphylococcus epidermidis: Review of 100 cases. Am J Med 77:639-644.
Mane, A.K., N.V. Nagdeo, V.R. Thombare. 2010 Study of neonatal septicemia in a tertiary care hospital in rural Nagpur. Journal of recent advances in applied sciences (jraas) 25:19-24.

Rahman, S., A. Hameed, M T Roghani, Z Ullah. 2002; Multidrug resistant neonatal sepsis in Peshawar, Pakistan. Arch Dis Child Fetal Neonatal Ed 87:F52-F54.

Reeta Rasaily: January-March 2009 Epidemiology of neonatal infections: Community experience Journal of Neonatology Vol. 23, No. 1

Roy, I., Jain A, Kumar M, Agarwal SK. 2002 Bacteriology of neonatal septicaemia in a tertiary care hospital of northern India. Indian J Med Microbiol; 20:156-9.

Rushda Aftab, Imran Iqbal. January - March 2009; changing pattern of bacterial isolates and their antibiotic sensitivity in neonatal septicemia: a hospital based study nishtar medical journal vol 1 , no 1 .

Sabel, K.G., and Hanson, LA.1974; The clinical usefulness of CRP determination in bacterial meningitis and septicaemia in infancy.Acta Paediatr.Scand.63:381

Shah, G.S., Budhathoki S, Das BK, Mandal RN. 2006; Risk factors in early neonatal sepsis. Kathmandu University Medical Journal, Vol. 4, No. 2, Issue 14, 187-191.

Shrestha, N.J., Subedi KU, Rai GK. 2011 Bacteriological Profile of Neonatal Sepsis: A Hospital Based Study. J Nepal Paedtr Soc;31(1):1-5.

Tallur, S.S., Kasturi AV, Nadgir SD, Krishna BV. 2000 Mar; Clinico-bacteriological study of neonatal septicemia in Hubli. Indian $\mathbf{J}$ Pediatr. 67(3):169-74.

\section{How to cite this article:}

Sabharritha Sekar, David Agatha and Selvi, R. 2017. Study of Microorganisms Causing Neonatal Sepsis in a Tertiary Care Hospital and their Antimicrobial Susceptibility Pattern. Int.J.Curr.Microbiol.App.Sci. 6(10): 669-677. doi: https://doi.org/10.20546/ijcmas.2017.610.082 